\title{
CARTOGRAFIA, ARTE E VISÕES DE MUNDO NA REPRODUÇÃO DO "MAPA INVERTIDO DA AMÉRICA DO SUL"
}

- CARLA MONTEIRO SALES*

Resumo: 7 "Mapa Invertida da América da Sul" é um reconhecida exemplo do que chamamos de mapa artísticas. Primeira, por ser um mapa que nãa fai feito pelos cânones da ciência cartagráfica, mas pelas mãos de um artista uruguaio, chamado Torres-Sarcía, em 1943. Segunda, porque sua apropriação cartográfica compõem o famoso redirecionamenta da panta da América da Sul para o topo da imagem. Terceira, par ser bastante repraduzida em diversos contextos até os dias atuais. Instigado por essas características da obra, o presente texto tem por abjetivo compreender as diversas contextos que reproduzem esse mapa e contribuem com a permanência de sua expressividade artística e discursiva. Para tanto, é necessário discutir as diversas visões de munda que podem ser expressas em um mapa artística que inverte a orientaçãa convencional da América da Sul, o que será feito através das relações entre cartografia, arte e gengrafia.

Palavras-chave: mapa, arte, visões de munda, América do Sul.

Introdução

As relações entre mapas e geografia são longínquas, o que não significa o esgotamento de suas análises e entendimentos. Pelo contrário, possibilita um enriquecimento de temas, enfoques e críticas que contribuem para sua renovação e relevância. Os vínculos entre cartografia e arte são uns dos desafios 
recentes para a abordagem da geografia frente aos mapas, pois expandem as características, as linguagens $\mathrm{e}$ as definições do mapa.

Tais desafios podem ser expressos pelos seguintes questionamentos: de quais modos a geografia pode utilizar mapas com qualidades mais artísticas do que científicas? Quais as contribuições de um mapa artístico para as análises geográficas? Quais metodologias se adequam a essas análises? $\mathrm{O}$ presente texto tem a pretensão de discutir tais questões através da análise de um dos mais recorrentes exemplos de mapas artísticos, o Mapa Invertido da América do Sul (figura 1).

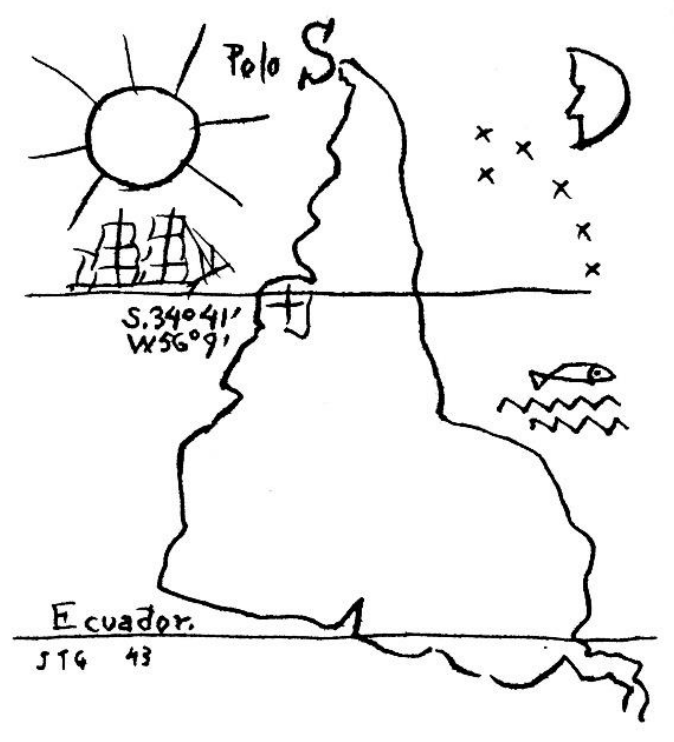

Figura 1 - Mapa Invertido da América do Sul. Fonte: INTENDENCIA DE MONTEVIDEO, 2015. Disponível em: <http://www.montevideo.gub.uy/jtg/por_escuela .html>. Acesso em: 20 jan. 2015.
Este não é um mapa como os convencionais, que costumam ser validados na ciência geográfica pelo emprego de escala, legenda, título ou dados georreferenciados. Também não é uma obra de arte usual, pois visualizamos claramente uma estética ou um contorno que reconhecemos como cartográfico. Por ser tanto um mapa, como uma obra de arte, enquadra-se no que é chamado de mapa artístico. Essa ambiguidade torna problemática a definição desses mapas, mas para fins práticos da presente análise, adotaremos a definição mais simplificada de apropriações de elementos da cartografia por artistas em suas obras.

Torres-García foi um desses artistas a utilizar mapas, publicando seu Mapa Invertido da América do Sul para inaugurar as atividades da Escola del Sur: El Taller Torres-García (TTG), em 1943. Nesse período, faziam alguns anos que o artista havia retornado à sua cidade natal Montevidéu, após crescer com o pai em Barcelona. Já adulto, mudou-se para Paris, e depois Nova Iorque, tendo alcançado relativo reconhecimento com suas obras. Em seu retorno, declarava o objetivo de desenvolver uma série de atividades que fomentassem a criação de um movimento artístico inovador e original, em Montevidéu, que acreditava poder igualar a arte de Paris (TORRES, 1992). 
Entretanto, esses objetivos encontram dificuldades pelo que o próprio artista descreveu como um gosto predominante nas artes uruguaias de copiar cânones estéticos do fin-de-siècle importados da Europa (TORRES, 1992). Assim, uma de suas primeiras atitudes, já em Montevidéu, foi escrever seu manifesto Estructura (1936), cuja capa era composta de uma primeira versão de seu mapa invertido e, através dele declara que:

É por isso que nós agora viramos o mapa de cabeça para baixo, e agora nós sabemos qual é nossa real posição, e não é como o resto do mundo gostaria que estivéssemos. De agora em diante, o alongamento da ponta da América do Sul irá apontar insistentemente para o Sul, nosso Norte. Nossa bússola também, ela vai inclinar irremediavelmente e para sempre na direção do Sul, da direção do nosso polo (TORRES-GARCÍA, 1992, p.53, tradução nossa) ${ }^{1}$.

Sua intenção com tal manifesto era expor o processo histórico da arte através de suas experiências, com grandes doses de opiniões pessoais. Também exaltava a cultura e os motivos do Uruguai e da América do Sul, combatendo o comportamento que ele chamou de "exilados da Europa”. Uma consciência que não era só de Torres-García, como também de outros artistas modernistas da América Latina, incomodados com as principais capitais latinas que não se apresentavam como sedes de sua sociedade.
Ao contrário, eram enclaves europeus, a conspirar traiçoeiramente ou a colaborar submissamente na exploração de matérias-primas naturais, ou como Lima, Rio de Janeiro e Buenos Aires, com as costas voltadas para o interior e mirando sonhadoramente o oceano, que reconduzia à Europa. Decerto, alguns escritores sempre alegaram que o cosmopolismo é uma aproximação inevitável, e ainda por cima desejável, do mundo, um desejo de inserir a América Latina na ordem universal das coisas, de fazê-la tomar seu lugar entre as culturas, reconhecendo e sendo reconhecida. Eis uma discussão cujo fim está longe (MARTIN, 2011, p. 356).

Com seu manifesto e seu atelier, Torres-García intencionava chamar atenção de novos artistas uruguaios para conformação de um movimento que fosse procedente da América do Sul, centrando em temas e problemas que não se religam à Europa. Por conta dessas aspirações, o 
artista foi inspirado a inverter o mapa da América do Sul e propor uma visão de mundo onde o Sul não seja mais dependente ou "inferiorizado", assumindo uma posição, que segundo o artista, lhe foi negada ao longo da história.

Somado à inversão do mapa da América do Sul, outros princípios de Torres-García também são perceptíveis na imagem, como o da arte construtivista. Esta corrente guiava-se na busca de um entendimento universal das artes e adotava os signos como algo natural, com isso, ele pode apreender a essência daquele ponto de incidência entre o existente e o abstrato (ADES, 1997). Artisticamente, Torres-García é reconhecido por essa estética quase rústica. Seus quadros, desenhos, murais e até esculturas são concebidos pela forma retangular onde as diferentes cores e os diferentes símbolos são associados. Assim,

Ele abstraia símbolos em linhas básicas de desenhos, acreditando que tais formas simplificadas seriam primordiais e, assim entendidas universalmente, e, em seguida, ele as construía em suas redes, criando um sistema de relações simbólicas formalmente estruturadas (JOLLY, 2011, p. 200, tradução nossa.)2.
Essa pretensão de elaborar um estilo artístico baseado no entendimento para o mundo, e não apenas na estética, era compartilhado por vários artistas do período, pois condizia com os princípios gerais modernistas. A singularidade de Torres-García não está, portanto, nos princípios básicos do construtivismo cuja origem era europeia, mas na incorporação de elementos e entendimentos indígenas, como a simbologia do sol e do peixe a esses princípios (TORRES, 1992). Em suma, Torres-García "praticou sua arte com a mão tipicamente trêmula - com 'sentimento', segundo jargão de estúdios emprestando às suas obras um estranho simbolismo. Nunca se viu nada igual no mundo” (BAYÓN, 2011, p. 609).

Portanto, são essas as convicções que guiaram a configuração do Mapa Invertido da América do Sul. Para expressála, o artista compõe uma reunião de elementos simbólicos de desenho simplificado e rústico, que intencionam despertar a ideia de atemporalidade e de entendimento universal. $\mathrm{O}$ que parece ter obtido sucesso, visto sua frequente reprodução atual. $\mathrm{O}$ propósito era incorporar um elemento figurativo ou o sujeito na estrutura, o artista penetra em sua ordem geométrica e estrutural, para sintetizá-lo, torná-lo uma ideia, a essência de si mesmo. 
A América do Sul é reduzida ao seu contorno, cujo único referencial cartográfico é a Linha do Equador que, convencionalmente, indica a divisão global entre hemisférios Norte e Sul. A precisão está na localização de Montevidéu destacada pelas coordenadas, que auxiliam a chegada do barco. Nem mesmo a designação da região é necessária, pois esta já é reconhecida pelo seu geo-corpo (NOVAES, 2014), previamente moldado e fixado pelos mapas tradicionais. Esse enquadramento do mundo via mapas padronizados tende a atender o objetivo geopolítico de classificar o que pertence e o que não pertence a tal localidade, e a estabelecer seu posicionamento "correto". Assim, o artista usa de uma das principais funções geopolíticas da cartografia: servir de ferramenta para modelar os formatos de países, regiões e continentes.

Com isso, Torres-Garcia foi um dos primeiros artistas do século $\mathrm{XX}$ a trabalhar com mapas, e dividiu com outros artistas a ideia de usar a América do Sul para evocar o pan-americanismo (JOLLY, 2011). Com tal proposta, ele construiu a ideia de inverter a orientação do mapa, de relativizar uma imagem padronizada de mundo para o entendimento de sua mensagem: valorizar as coisas locais da América na construção de um novo mundo e que, portanto, necessitava de um novo mapa.

\section{Cartografia e Arte}

Ao reaproximar cartografia e arte, os mapas artísticos levantam uma série de questões sobre as relações históricas e intercâmbios representativos que esses dois campos apresentam. No passado, separar arte e mapeamento não era uma tarefa simples, visto que mapear e pintar paisagens eram atividades feitas pelas mesmas mãos (REES, 1980). Mapas tinham qualidades estéticas, elementos simbólicos e visões de mundo subjetivas tal qual as pinturas. Não é à toa que as capitais da arte renascentista, como Veneza e Antuérpia, eram também centros proeminentes de confecção de mapas.

Essa íntima relação foi sendo gradativamente enfraquecida desde, pelo menos, a instituição da cartografia enquanto uma disciplina acadêmica, do campo das ciências exatas, ao longo do século XV. Para isso, o mapeamento estabeleceu uma série de critérios, cálculos, instrumentos e técnicas que instituíram o período moderno dos mapas. Seu conjunto de elementos obrigatórios, escalas numéricas, formas padronizadas, passam a compor a estética geral que identificamos como mapa e, por 
conseguinte, o torna diferente das demais formas de representação.

Assim, durante muito tempo, a história da cartografia foi contada a partir de uma perspectiva evolutiva (COSGROVE, 2005), onde os mapas teriam sido gradativamente aprimorados por meio de novas técnicas científicas e de precisão. Como resultado, configurou-se uma oposição entre mapas pré-modernos e modernos: os primeiros seriam carregados de subjetividade e imprecisão, por serem influenciados pela arte; já os segundos seriam acurados e objetivos em suas representações, influenciados pela razão científica.

Nesse processo, a fantasia do incógnito vai sendo substituída pela informação do conhecimento, e as imagens pictóricas pelos signos convencionados. Uma mudança que corresponde as necessidades dos séculos XIV/XV, quando a expansão marítima, a divisão de terras, a exploração colonial e as rotas de comércio foram se expandindo, e passaram a requerer o uso de mapas mais padronizados e matematicamente fundados.

É claro que existia uma importante demanda para tais transformações no mapeamento e uma indiscutível relevância e funcionalidade da cartografia científica. princípios e características, a cartografia moderna também menosprezou e invalidou as demais formas de mapeamento, como o pré-moderno ou de culturas orientais, com o objetivo de apagar os vestígios do fazer artístico dos mapas (HARLEY, 1989). Por muito tempo, esse modelo prevaleceu na história da cartografia fomentando estudos que mostrassem a influência das artes apenas nos mapas pré-modernos, evitando o exame crítico da ciência cartográfica no século XX, e deixando intacta a impressão de que arte e cartografia seguiram caminhos diferentes no período moderno (COSGROVE, 2005).

Essa história começa a adquirir novas versões através de uma corrente de pensamento que ficou conhecida como cartografia crítica, que se desenvolve no início da década de 1980 e propõe que os mapas não apenas representam, mas também fazem a realidade (CRAMPTON E KRYNGIER, 2006). Nesse sentido, os mapas são vistos como ativos, com capacidade de construir ativamente no conhecimento espacial, de exercer poder e de promover mudanças sociais. $\mathrm{O}$ mapeamento seria parte integrante da produção do espaço, da geografia e das identidades políticas das pessoas que habitam e consomem um lugar.

Entretanto, além de estimular seus 
Enquanto as regras da cartografia científica tendem a padronizar os mapas, a cartografia crítica tende a ampliar suas formas, colocando sua representação como algo relativo e influenciável. Porém com um adendo importante, sem menosprezar essa manipulação, visto que os mapas expressam uma forma possível de ver o mundo, dentre várias existentes. A superação dessa dicotomia é o que favorece à cartografia crítica a expandir as análises e reconhecimentos dos mapas para suas mais variadas linguagens: artística, jornalística, propagandista ou dos períodos pré-modernos, por exemplo.

Diante dessa perspectiva crítica, historiadores da cartografia da década de 1980 “(...) procuraram trazer um novo pensamento crítico sobre a interpretação de mapas e tentaram ampliar nossa compreensão das práticas de mapeamento, não obstante a historiografia convencional de evolução cartográfica da arte à ciência" (COSGROVE, 2005, p. 35, tradução nossa) $)^{3}$. No lugar dessa visão evolutiva e binária, a proposta é compreender as interseções entre as práticas artística e cartográfica, bem como perceber o mapa como um produto cultural e social que precisa ser entendido em seu contexto histórico.

Ao aproximar artes e mapas, encontramos paralelos imediatos entre esses dois tipos de imagens pictóricas ou cartográficas. Em Wood (2006), o argumento é que ambos são artefatos gráficos, seguem lógica de escolhas e omissões como qualquer representação, e são primordialmente comunicacionais. Isso quer dizer que ambos são construções pelas quais uma pessoa (ou grupo de pessoas) sensibilizam outras, afetam seu estado ou seu comportamento, em uma situação comunicativa. Complementarmente, em Cosgrove (2005) o destaque é para as questões técnicas compartilhadas entre essas duas práticas, como ênfases, meios, linhas, cores e simbolizações. Também compartilham de decisões parecidas sobre forma, composição, enquadramento e perspectiva.

Essa paridade entre cartografia e arte é exposta e provocada pelos mapas artísticos, reconfigurando suas relações. De fato, quando artistas misturam elementos característicos da estética cartográfica às suas técnicas artísticas, tem-se uma linguagem pouco usual, que expõe relações espaciais que são evitadas, ou pouco exploradas, pelos mapas convencionais da ciência cartográfica. Os mapas artísticos ampliam as formas de representar o mundo de modo mais espontâneo e compassivo, traçam uma associação entre forma estética e contextos políticos, que questionam as 
relações de poder da cartografia em afirmar um mundo padronizado.

Nas análises sobre mapas artísticos não cabe verificar suas conformidades técnicas ou precisão de proporções, o que está em tela são as funções sociais, tanto as que influenciam como as que são influenciadas por eles. As propostas artísticas de mapa têm essa capacidade de sensibilizar e causar reflexão sobre nossas relações com os espaços, reais ou imaginados. As possibilidades não findam.

O que está em questão é a natureza do mundo em que queremos viver. Ao apontar para a existência de outros mundos - reais ou imaginadosartistas de mapa estão reivindicando o poder do mapa de alcançar outros fins além da reprodução social de um status quo. Mapas artísticos não rejeitam os mapas. Eles rejeitam a autoridade clamada pelos mapas normativos exclusivamente para tratar a realidade como ela é, ou seja, com imparcialidade e objetividade (WOOD, 2006, p. 10, tradução nossa, grifo no original $)^{4}$.

Com efeito, o ato de mapear, seja artístico ou científico, é um ato de criatividade, pois formam a expressão de um conhecimento sobre o mundo (CRAMPTON, 2010). A diferença é que no contexto científico existem regras que guiam e limitam essa representação, colocando-as como precisas e corretas expressões de um mundo que é único. Enquanto, no contexto artístico, essas expressões são guiadas por anseios culturais e ideológicos, que são assumidamente colocados, configurandoas como uma imagem possível e contextualizada de mundo.

É nesse sentido que os mapas artísticos se tornam um importante meio de compreensão das visões de mundo, compondo um tipo particular de representação que associa forma estética às relações de poder sobre o espaço, ressaltando críticas e expressividades que não cabem na normatização da cartografia científica. Assim é com o Mapa Invertido da América do Sul, queremos compreender a expressividade de sua visão de mundo tanto em seu passado contexto de elaboração, como em seus atuais contextos de reprodução e apropriação.

\section{Visões de mundo na reprodução do “Mapa Invertido da América do Sul'}

Torres-García virou a América de cabeça para baixo, invertendo a posição do Sul em sua obra artística e provocando tanto estranhamento quanto admiração. 
Mas virar o mapa "ao contrário" é mais do que um efeito curioso, é contrariar uma representação canônica, estabelecida e hegemônica de mundo que, por sua vez, tem ampla influência das relações de poder nas formas do conhecimento.

Como já vimos anteriormente, os ideais do artista e o contexto histórico de elaboração do Mapa Invertido da América do Sul dizem muito sobre os significados e objetivos então pretendido por essa obra: romper a dependência política e cultural com a Europa, exaltar os motivos próprios da América do Sul através de um movimento artístico original e valorizar a própria região através de uma nova posição no mundo. Entretanto, a expressividade desse mapa artístico não ficou restrita ao seu contexto de criação. Ela foi estendida por sua reprodução nos mais diversos meios que vão desde livros didáticos a tatuagens.

Da mesma forma, essa obra ultrapassou também as limitações temporais, visto que, mesmo sendo divulgada em 1943, é possível achar exemplos de sua reprodução até os dias atuais. Logo, não é difícil encontrarmos pessoas familiarizadas com tal imagem, o que é, provavelmente, explicado pela sua ampla circulação. Caiu no gosto popular, ganhou fama e passou a emprestar seu ideário a diferentes tipos de conjunturas, tornando-se um exemplo notório e didático para idealização do que é um mapa artístico.

Assim, torna-se interessante compreender quais contextos contribuem para a manutenção de sua fama na atualidade, passados mais de setenta anos. Esses contextos mantém a expressividade artística e discursiva do mapa construtivista de Torres-García? Ou lhe dá novas significações e utilidades? Se retomarmos a ideia dos mapas artísticos como construções que visam contrapor, questionar ou contrariar as formas hegemônicas e padronizadas de mapa, então a contínua reprodução do Mapa Invertido da América do Sul deve supor a continuidade dos mesmos questionamentos de sua elaboração?

Primeiramente, temos claro que a reprodução de uma obra não necessariamente carrega consigo toda a história da obra, ou mesmo conserva todas as formatações originais. Não é por ver, ou mesmo utilizar de alguma forma esse mapa artístico que se passa a dominar todos seus discursos ou propósitos que inspiraram o artista a fazê-lo. Na verdade, Benjamin (2012) vai além, afirmando ser impossível total conservação: "Mesmo na reprodução mais perfeita falta algo: o aquie-agora da obra de arte - sua existência única no lugar em que está. Mas é nessa 
existência única, e somente nela, que transcorre sua história” (p. 12).

Em outras palavras, para o autor, a reprodutibilidade técnica extingue a autenticidade daquilo que foi reproduzido, colocando tal cópia em situações totalmente improváveis ao próprio original. Se por um lado podem ocorrer perdas de essências ou de elementos técnicos nesse processo de reprodução, por outro lado também podem ocorrer acréscimos de situações, públicos e leituras com capacidade de potencializar ou pluralizar os discursos associados à obra.

Dentre os diversos fatores que podem levar a reprodução de uma imagem em contextos tão diversos, adquire destaque a identificação com sua mensagem. As formas artísticas admitem interpretações amplas sobre os discursos que expressam, tornando um desafio delimitar um sentido único ou original da obra. Mas tão importante quanto esse sentido primordial, é compreender os outros discursos que também passam a ser entendidos e vinculados por essa construção artística através de sua apropriação.

Então, para possibilitar a análise dos contextos e dos discursos que se apropriam dessa obra, compomos um levantamento eventual de imagens que mostram o Mapa Invertido da América do Sul em alguma de suas muitas reproduções. Para destacar as semelhanças, complementariedades e diversidades dessas reproduções, compomos uma separação por grupos temáticos e faremos uma breve descrição das informações de cada um desses temas. Ao final, a percepção acumulada de similaridades nos encaminha para compreender a continuidade e difusão da visão de mundo questionadora desse mapa artístico.

O primeiro grupo temático é composto de souvenires do Uruguai, país de origem da obra (Figura 2). Nesse contexto, a obra de Torres-García é reproduzida em diferentes objetos: camisas, cartões-postais, canecas e cadernos que podem ou não ser somados a outras referências locais. Assim, o Mapa Invertido da América do Sul empresta sua expressividade para ser vendido e consumido como um referencial do seu país de origem e, logo, da localidade que ele inverte. 


\section{7:}

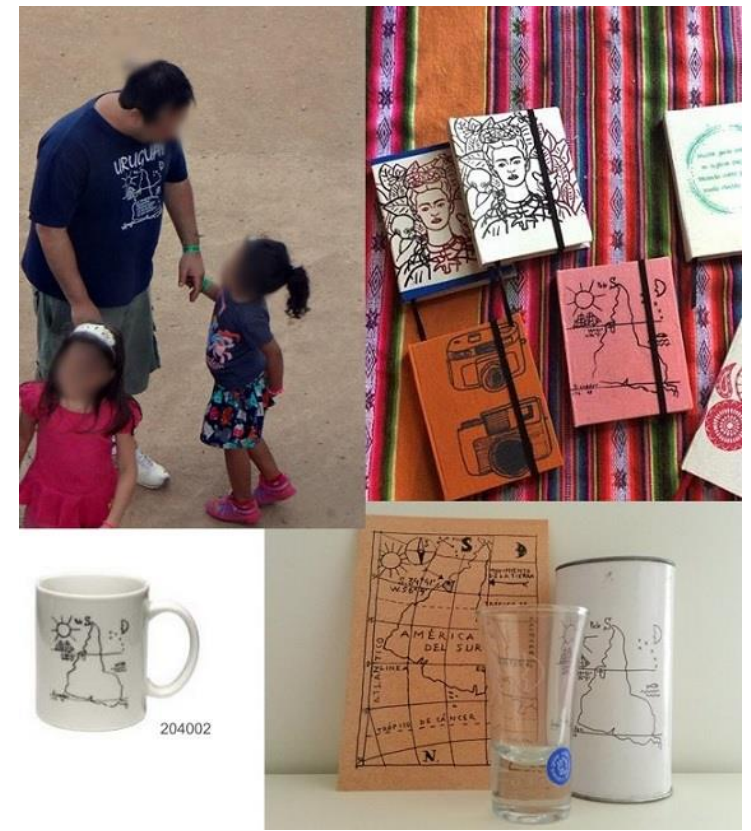

Figura 2 - Reprodução em souvenires. Esquerda superior - Fonte: O autor, fotografado em 30 dez. 2014, no Parque Sarah Kubitschek, em Brasília. Direita superior - Fonte: O autor, fotografado em 27 abr. 2016. Esquerda inferior - Fonte: http://www.torresgarcia.org.uy/, acesso em 10 jan. 2015. Direita inferior - Fonte: O autor, fotografado em 10 jan. 2015

Além da sua utilidade turística, o Mapa Invertido da América do Sul também é aproveitado na temática escolar (figura 3) para fins educativos do Ensino Fundamental e Médio. Nesse tema, encontramos dois exemplos em livros didáticos do Ensino Fundamental, onde esse mapa artístico serve para refletir sobre as visões de mundo da América do Sul e questionar a padronização de uma orientação cartográfica ao Norte. E mais um exemplo na questão de um simulado feito pelo Ministério da Educação, em 2012, para o Exame Nacional do Ensino Médio (ENEM), onde o aluno é convidado a pensar no significado que dessa inversão de orientação no contexto de questionamento das visões eurocêntricas de mundo.

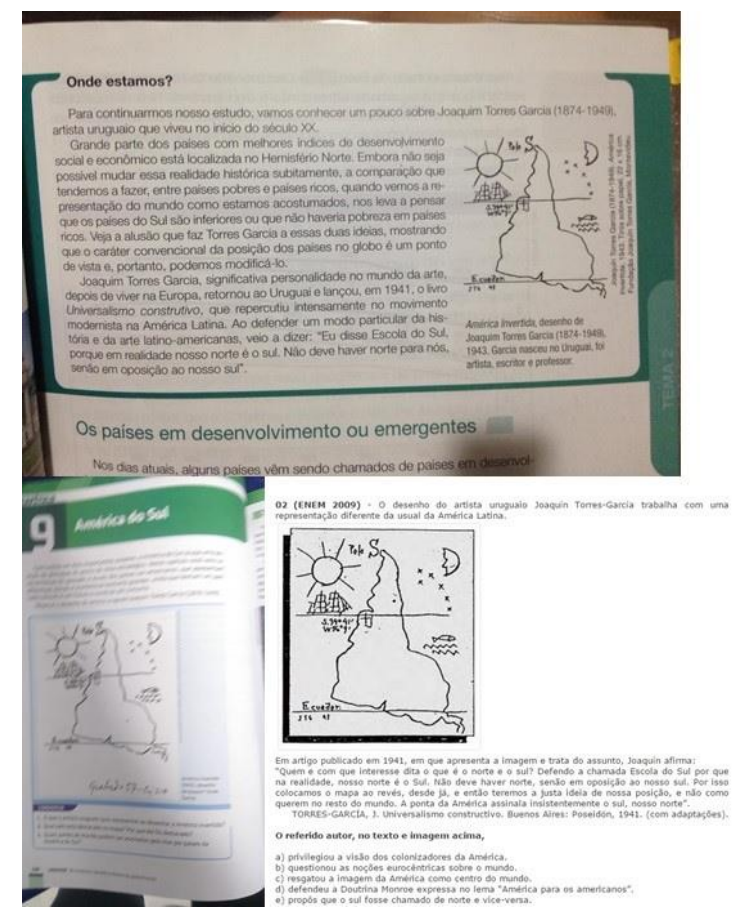

Figura 3 - Reprodução em ferramentas escolares. Superior - Fonte: "Geografia nos dias de hoje", Editora leYa, 2015. Esquerda inferior - Fonte: "Por dentro da Geografia", Editora Saraiva, 2016. Direita inferior - Fonte: Ministério da Educação, 2012.

Também no âmbito do conhecimento, o terceiro tema é composto pelo contexto acadêmico (figura 4), mas não consideramos livros, capítulos e artigos destinados ao estudo da obra de Torres-García. Encontramos o Mapa Invertido da América do Sul ilustrando livros e cartazes de divulgação de eventos acadêmicos cujo tema poderia ser representado por essa obra. A primeira 
imagem é um cartaz de divulgação do evento "I seminário de Geografia e giro descolonial: experiências, ideias e horizontes de renovação do pensamento crítico", realizado em 2014 na Universidade Federal Fluminense (UFF), onde o mapa de Torres-García parece dialogar com o tema do evento em criticar a dependência dos países do Sul e desejo por novas perspectivas a serem traçadas também no debate acadêmico. A segunda imagem é a capa do livro que traduz a obra “O que é a Geografia?”, do geógrafo Ruy Moreira, para o espanhol e, nesse sentido, o mapa artístico ilustra uma ideia do interesse dessa ciência. A terceira imagem também é um cartaz de divulgação, dessa vez do evento "Universidades e movimentos sociais na América Latina: pesquisa militante, construção de conhecimento e bens comuns", realizado em 2014, na Universidade Federal do Rio de Janeiro (UFRJ). Nessa imagem, o mapa artístico representa o engajamento de diferentes campos, como a arte e a ciência, nas lutas pelos anseios e demandas da América Latina. Por fim, a última imagem é capa do livro "Conocer desde El Sur: para uma política emancipatória” do sociólogo português Boaventura de Souza Santos. O título da obra acadêmica adquire ampla relação com o mapa invertido de Torres-
García que, ao apontar o Sul para o topo, revoga qualquer dependência ou subalternização dos conhecimentos originados do Sul global.

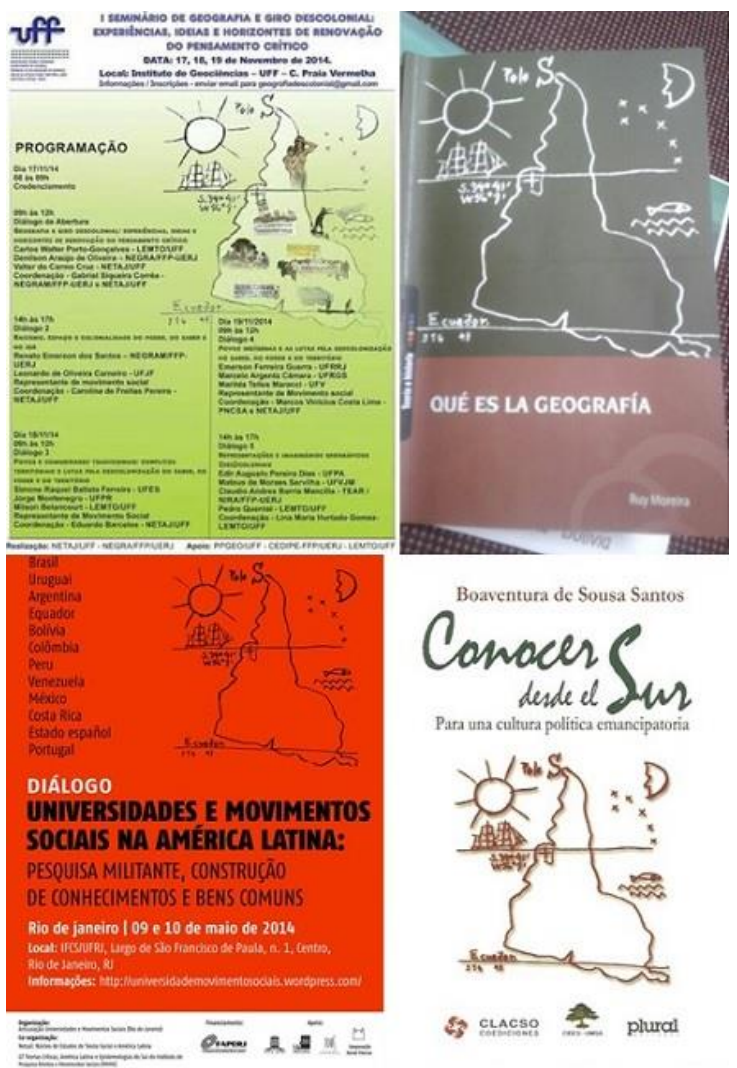

Figura 4 - Reprodução em contextos acadêmicos. Esquerda superior - Fonte: Evento I Seminário de Geografia e giro descolonial, nov. 2014. Direita superior - Fonte: Fotografado por André Novaes, abr. 2017. Esquerda inferior - Fonte: Evento Universidades e Movimentos Sociais na América Latina, maio 2014. Direita inferior - Fonte: “Conocer desde El Sur”, 2006.

Por fim, o último grupo temático é bastante difundido, com inúmeros exemplos, mas com maior dificuldade de obtenção de imagens por fazer parte do corpo das pessoas, em tatuagens (Figura 5). As situações em que conseguimos fotografar tais tatuagens indicam certa 
ideologia dessas pessoas, e como esta pode estar relacionada a esse mapa artístico. Claramente, existem outros inúmeros outros contextos e lugares que essas pessoas, tatuadas com o mapa de TorresGarcía, circulam. Não é nossa intenção traçar um perfil social e psicológico de cada uma delas, mas apenas a situação específica em que foram fotografas. Destarte, a primeira imagem traz um militante do Movimento Nacional de Luta pela Moradia (MNLM); a segunda uma participante da Conferência Nacional de Cultura; e a terceira, um adepto do carnaval de rua não-oficial do Rio de Janeiro (Bloco "Boi Tolo" não compõe a agenda oficial da prefeitura). Os lugares em que tais tatuagens foram encontradas sugerem manifestações sociais que questionam ou tentam mudar uma realidade estabelecida, seja na forma de uma conferência, de um ato político, ou mesmo do carnaval de rua em um bloco não gerenciado pela prefeitura.

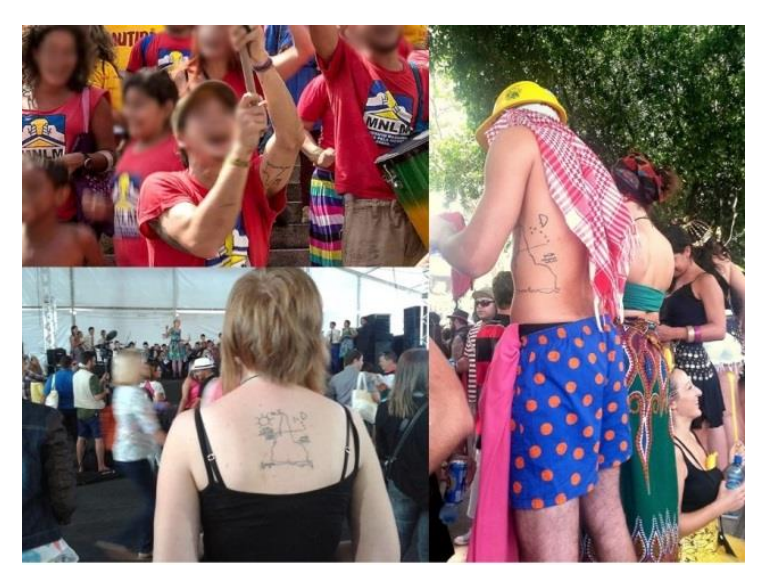

Figura 5 - Reproduções em tatuagens. Esquerda superior - Fonte: Fotografada na Jornada de luta pelo direito à moradia do MLNM,em 15/04/2015. Arquivo de Mariana Moraes. Esquerda inferior Fonte: Fotografada na III Conferência Nacional de Cultura, 2013, em Brasília. Disponível em: <http://edgarb.blogspot.com.br/2013/12/embrasilia-iii-conferencia-nacional-de.html>. Acesso em: 17 mar. 2015. Direita - Fonte: O autor, fotografada no carnaval de rua do Rio de Janeiro, na Praça Tiradentes, Centro, no dia 14 fev. 2015.

Destarte, esse conjunto de imagens que reunimos e descrevemos brevemente buscou ressaltar a notoriedade e expressividade com que o mapa artístico de Torres-García permanece na atualidade. Nosso intuito foi compor diferentes universos que demonstrassem a diversidade de situações para a qual tal obra tem serventia e identificação, indicando também, a amplitude de sua circulação. Nesse sentido, é crucial associar tal sucesso às características fundamentais da obra. O Mapa Invertido da América do Sul é, resumidamente, um mapa artístico de estética construtivista, com a orientação invertida, e por tal viés, fornece uma visão de mundo distinta e insubordinada.

Entretanto, tais características só adquirem relevância e significado se reconhecemos o poder dos mapas em representar visões de mundo. Especificamente falando, mapas não são ferramentas neutras e transparentes de mensuração e descrição de um espaço. A institucionalização cientifica da cartografia 
não é capaz de eliminar as imaginações, seleções e omissões do mapa, por esse ainda ser uma forma de representação, como tantas outras. Apesar de conseguir disfarça-las por meio de suas padronizações.

Assim, como o mundo não é tátil, sendo impossível experimentar fisicamente toda superfície terrestre, essa experiência passa a ser guiada pelas formas de representação do mundo. O mundo passa a ser conhecido através de sua representação e estas que dão forma aos entendimentos e ações sobre o mundo, moldando grande parte das comunicações e relações entre as pessoas (COSGROVE, 2001). Nesse sentido, o mapa exerce um importante papel na visualização e afirmação do conhecimento geográfico, seu poder de influência chega às formas de pensar, teorizar, agir e relacionar os espaços globais.

Destarte, o domínio sobre as formas de representação do mundo se tornaram muito mais importantes e influentes do que um simples esquema gráfico. Em princípio, o mapa constitui uma visão de mundo, porém quando são institucionalizados e padronizados passam a formas pelas quais o mundo pode ser formado (WOOD, 2010). O modo como conhecemos o mundo, interligamos seus espaços e relacionamos suas distâncias passam, então, a ser guiadas por essa representação de mundo dominante.

É diante desses entendimentos que os mapas passam a despertar, cada vez mais o interesse de artistas em apropriar seus elementos, sua estética e, logo, sua autoridade em representar e formar o mundo como conhecemos. Até porque a prática artística também se interessa por conflitos e reconfigurações do espaço. Em termos históricos, esse interesse pode ser vislumbrado no papel da arte em questionar ou contribuir na formação dos Estados, no nacionalismo e no imperialismo (INGRAM, 2013).

Já o interesse desses artísticas pelos mapas, para Cramptom (2010), sustenta que os mapas são políticos mesmo sem afirmarem ser. Para ele, os mapas artísticos têm, em definição, princípios políticos, pois mesmo que não seja seu foco, os mapas artísticos readéquam elementos ligados à autoridade e ao poder científico da cartografia. E, portanto, expõem (e, muitas vezes revertem) a contribuição política das representações cartográficas.

De fato, as representações artísticas de mapa podem apresentar diversas propostas, mas é notória a recorrência das questões políticas do espaço. Quando artistas fazem mapas, eles 
são motivados pela sua relação com o espaço, percebendo mudanças, intervenções, desigualdades e exercícios de poder. Esse tipo de mapa relaciona representações de mundo com as relações de poder e motivações ideológicas de forma autêntica e assumida.

A inversão da América do Sul no mapa de Torres-García demonstra a capacidade de reformular o que foi previamente estabelecido. E o que está estabelecido através dos mapas é mais do que meros atributos de uma determinada porção da superfície terrestre, é também o domínio sobre as formas pelas quais passamos a compreender esse mundo.

Tendo isso em vista, a reprodução do Mapa Invertido da América do Sul em contextos atuais não está relacionada apenas às suas qualidades artísticas, mas principalmente aos discursos políticos associados a ele. Destacadamente, a possibilidade de formulação de novas perspectivas de mundo e novas possibilidades de entende-lo, condizentes com as demandas desses contextos que são expressas através da inversão da orientação com o Sul no topo do mapa.

\section{Considerações finais}

Por sua proposta de apropriação de elementos cartográficos, os mapas artísticos são alternativos quase que por definição. Tais construções tendem a mostrar mundos reformulados, imaginados ou compassivos, expressos pela adaptação da estética cartográfica. São comprometidos com a sensibilidade, criatividade e liberdade de expressar o mundo ao seu redor e, portanto, alternos à representação padronizada e cientificamente guiada.

No último século, e especialmente nos últimos 30 anos, artistas fizeram mapas, subverteram mapas, realizaram itinerários, contestaram fronteiras, traçaram o invisível, e invadiram espaços físicos, virtuais e híbridos em nome de cartografia (D’IGNAZIO, 2009, p.190, tradução nossa $)^{5}$.

Assim, o Mapa Invertido da América do Sul é tanto uma obra de arte de qualidades estéticas como uma representação de mundo. Sua notoriedade se deve aos discursos que foram expressos através desse meio de representação, tal qual apontaram nossos exemplos anteriores. Ao inverter a posição do Sul em seu mapa, Torres-García abarca também a inversão dos sentidos e caracterizações que as divisões geopolíticas do globo ajudaram a associar 
a essa região. Nesse sentido, realocar o Sul em uma posição superior do mapa, era uma forma de mudar, simbolicamente, as diferentes condições de dependência.

Destarte, o que Torres-García fez foi questionar uma imagem canônica que, ao longo da história, serviu à diversas significações e relações de poder. Sendo assim, a inversão de sua orientação passa a conotar uma série de valores simbólicos. O Mapa Invertido da América do Sul “(...) definiu um rumo para inúmeras outros artistas, geógrafos, educadores e outras pessoas a questionar a orientação padrão e projeção do mapa do mundo" (D'IGNAZIO, 2009, p. 195, tradução nossa $)^{6}$.

Os mapas artísticos e suas apropriações tendem a provocar perguntas, são imponentes ferramentas para relembrar que nossa relação com o espaço são construções sociais (JOLLY, 2011). E, por fim, podem trilhar novas perspectivas que favoreçam $o$ reconhecimento da pluralidade nas formas de representar ou resumir o mundo, cujo alcance não precisa ficar restrito a esses mapas, podendo alcançar outras formas artísticas, teorizações acadêmicas, práticas políticas, ou mesmo a cartografia científica.

\section{NOTAS}

* Doutoranda do Programa de Pós-graduação em Geografia da Universidade Federal Fluminense (PosGeo - UFF). Mestre em Geografia pelo Programa de Pós-Graduação em Geografia da Universidade do Estado do Rio de Janeiro (PPGEO - UERJ) e bacharelada e licenciada em Geografia pela mesma instituição. É professora contratada do Departamento de Geografia Humana, no Instituto de Geografia da Universidade do Estado do Rio de Janeiro (IGEOG - - UERJ). carla.msales@gmail.com

${ }^{1}$ That is why we now turn the map uspside down, and now we know what our true position is, and it is not the way the rest of the world would like to have it. From now on, the elongated tip of South America will point insistently at the South, our North. Our compass as well; it will incline irremediadiably and forever toward the South, toward our pole.

${ }^{2}$ He abstracted symbols into basic line drawings, believing that such simplified forms would be primal and thus universally understood, and then he built them into his grids, creating a system of formally structured symbolic relationships.

${ }^{3}$ (...) sought to bring new critical thinking to bear on the interpretation of maps and tried to broaden our understanding of mapping practices, not least the conventional historiography of cartography's evolution from art to science

${ }^{4}$ What is at stake is the nature of the world we want to live in. In pointing towards the existence of other worlds - real or imagined -map artists are claiming the power of the map to achieve ends other than the social reproduction of the status quo. Map artists do not reject maps. They reject the authority claimed by normative maps uniquely 
to portray reality as it is, that is, which dispassion and objectivity.

${ }^{5}$ In the last century, and especially in the last 30 years artists have made maps, subverted maps, performed itineraries, contested borders, charted the invisible, and hacked physical, virtual, and hybrid spaces in the name of cartography.

6 (...) set a course for numerous other artists, geographers, educators, and others to question the default orientation and projection of the world map.

\section{REFERÊNCIAS BIBLIOGRÁFICAS}

ADES, Dawn. Arte na América Latina: a era moderna 1820-1980. São Paulo: Cosac e Naify Edições, 1997.

BAYÓN, Damián. A Arte e a Arquitetura Latino Americanas, c. 1920 - c. 1990. In: BETHELL, Leslie. História da América Latina: A América Latina pós-1930: Ideias, Cultura e Sociedade. Tradução Gilson Cesar Cardoso de Sousa. São Paulo: EdUSP, 2011.

BENJAMIN, Walter. A obra de Arte na era da sua reprodutibilidade técnica. In: BENJAMIN, Walter; SCHÖTTKER, Detlev; HANSEN, Mirian; BUCKMORSS, Susan. Benjamin e a obra de arte: técnica, imagem, percepção. Tradução: Marijane Lisboa e Vera Ribeiro. Rio de Janeiro: Contraponto, 2012.

COSGROVE, Denis. Apollo's Eye: a cartographic genealogy of the Earth in the Western Imagination. Baltimore: Johns Hopkins University Press, 2001.

COSGROVE, Denis. Maps, Mapping, Modernity: Art and Cartography in the Twentieth Century. Imago Mundi, v. 57, p. 35-54, 2005.

CRAMPTON, Jeremy; KRYGIER, John. An Introduction to Critical Cartography, $A C M E$ : $A n$ International E-Journal for Critical Geographies, 4(1), p. 11-33, 2006.
CRAMPTON, Jeremy. Mapping: A Critical Introduction to Cartography and GIS. Oxford: Blackwell Publishing, 2010.

D'IGNAZIO, Catherine. Art and Cartography. In: KITCHIN, Rob; THRIFT, Nigel. (Orgs.) International Encyclopedia of Human Geography. Oxford: Elsevier, 2009. v. 1, p. 190-206.

HARLEY, Brian. Deconstructin the map. Cartographica. v. 26, n. 2, p. 1-20, 1989.

INGRAM, Alan. Artists. In: DODDS, Klaus; KUUS, Merje; SHARP, Joanne. The Ashgate Research Companion to Critical Geopolitics. Farnham: Ashgate, 2013.

JOLLY, Jennifer A. Reordering Our World. In: DYM, Jordana; OFFEN, Karl. Mapping Latin America: A cartographic reader. Chicago: The University of Chicago Press, 2011.

MARTIN, Gerald. A narrativa latino-americana, c. 1920 - c.1990. In: BETHELL, Leslie. História da América Latina: A América Latina pós-1930: Ideias, Cultura e Sociedade. Tradução Gilson Cesar Cardoso de Sousa. São Paulo: EdUSP, 2011.

NOVAES, André. Map art and popular geopolitics: mapping borders. between Colombia and Venezuela. Geopolitics, v. 19, 2014.

REES, Ronald. Historical Links between Cartography and Art. Geographical Review, v. 70, n. 1, p. 60-78, 1980.

TORRES, Cecilia. The School of the South: The Asociación de Arte Constructivo, 1934-1942. In: RAMÍREZ, Mari. (Org.). El Taller Torres-García: The School of the South and Its Legacy. Austin: University of Texas Press. 1992.

TORRES-GARCIA, Joaquín. The School of South. In: RAMÍREZ, Mari. (Org.). El Taller TorresGarcia: The School of the South and Its Legacy. Austin: University of Texas Press. 1992.

WOOD, Denis. Map Art. Cartographic Perspectives, n. 5 p. $6-12,2006$. 


\section{CARTOGRAPHY, ART AND WORLD VISIONS ON THE REPRODUCTION OF THE "INVERTED}

\section{MAP OF SOUTH AMERICA"}

abSTRACT: the "INVERTED MAP OF SOUtH AMERICA" is a RECOGNIZED EXAMPLE OF WHAT CAN BE CALLED aRTISTIC MAP. FIRST, BECAUSE thIS MAP WAS NOT MADE BY THE CANONS OF CARTOGRAPHIC SCIENCE, BUT BY THE HANDS OF A URUGUAYAN ARTIST, CALLED tORRES-garCí, IN 1943. SECOND, BECAUSE the CARTOGRAPHIC APPROPRIATION OF thIS WORK OF ARE COMPOSE the FAMOUS REDIRECTION OF THE TIP OF SOUTH AMERICA TO THE TOP OF THE IMAGE. THIRD, BECAUSE IT IS WIDELY REPRODUCED IN DIFFERENT CONTEXTS UNTIL THE PRESENT DAY. INSPIRED BY THESE CHARACTERISTICS OF thE WORK, tHE PRESENT PAPER AIMS TO UNDERSTAND the VARIOUS CONTEXTS that REPRODUCE tHIS MAP AND CONTRIBUTE TO the PERMANENCE OF ITS ARTISTIC AND DISCURSIVE EXPRESSIVENESS. THEREFORE, IT IS NECESSARY tO DISCUSS the various WORLDVIEWS that CAN BE EXPRESSED IN AN ARTISTIC MAP that REVERSES the CONVENTIONAL ORIENTATION OF SOUTH AMERICA, WHICH WILL BE DONE THROUGH THE RELATIONS BETWEEN CARTOGRAPHY, ART AND GEOGRAPHY.

KEY-WORDS: MAP, ART, WORLDVIEWS, SOUTH AMERICA.

\section{CARTOGRaFía, aRTE Y VISIONES DE MUNDO EN LA REPRODUCCIÓN DEL "MAPA INVERTIDO DE LA AMÉRICA DEL SUR"}

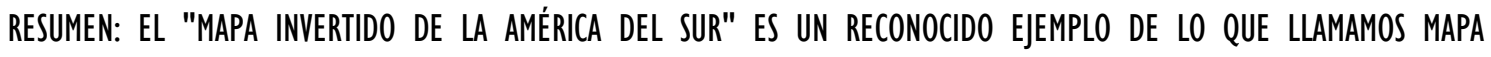
artístico. en PRIMER LUGAR, POR SER UN MAPA QUE NO FUE HECHO POR LOS CÁNONES DE LA CIENCIA CARTOGRÁFICA,

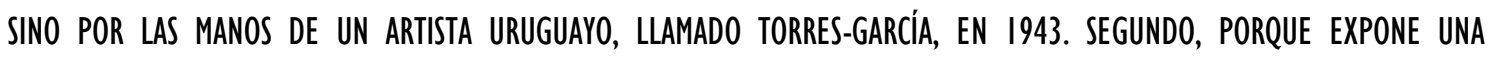
apropiación Cartográfica QUE COMPONEN EL FaMOSO REDIRECCIONAMIENTO DE LA PUNTA DE AMÉRICA DEL SUR PARA la PARTE SUPERIOR DE LA IMAGEN. TERCERO, POR SER BASTANTE REPRODUCIDO EN DIVERSOS CONTEXTOS hasta LOS días ACTUALES. INSTIGADO POR ESAS CARACTERÍSTICAS DE LA OBRA, EL PRESENTE TEXTO TIENE POR OBJETIVO COMPRENDER LOS DIVERSOS CONTEXTOS QUE REPRODUCEN ESE MAPA Y CONTRIBUYEN CON LA PERMANENCIA DE SU EXPRESIVIDAD ARTísTICA Y DISCURSIVA. PARA ELLO, ES NECESARIO DISCUTIR LAS DIVERSAS VISIONES DE MUNDO QUE SE PUEDEN EXPRESAR EN UN MAPA ARTísticO QUE INVIERTE LA ORIENTACIÓN CONVENCIONAL DE AMÉRICA DEL SUR, LO QUE SE HARÁ A TRAVÉS DE LAS RELACIONES ENTRE CARTOGRAFíA, ARTE Y GEOGRAFÍA.

PALABRAS CLAVE: MAPA, ARTE, SUR, VISIONES DE MUNDO, AMÉRICA DEL SUR. 